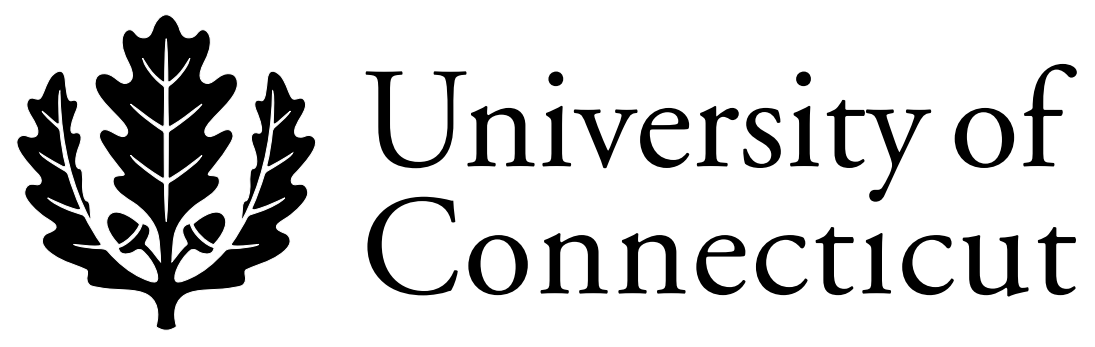

Department of Economics Working Paper Series

Should Victims of Exposure to a Toxic Substance Have an Independent Claim for Medical Monitoring?

Thomas J. Miceli

University of Connecticut

Kathleen Segerson

University of Connecticut

Working Paper 2002-41

July 2001, revised January 2002

341 Mansfield Road, Unit 1063

Storrs, CT 06269-1063

Phone: (860) 486-3022

Fax: (860) 486-4463

http://www.econ.uconn.edu/ 


\begin{abstract}
Traditional tort law does not allow a victim of exposure to a toxic substance to seek damages without evidence of actual loss. Given the difficulty of collecting damages after a long latency period, however, we examine the desirability of granting exposure victims an independent cause of action for medical monitoring at the time of exposure. We show that such a cause of action is not necessary to induce victims to invest in efficient monitoring. It can, however, increase incentives for injurer care, but only at the cost of greater litigation costs. The general reluctance of courts to adopt a cause of action reflects their recognition of this trade-off.
\end{abstract}




\title{
Should Victims of Exposure to a Toxic Substance Have an Independent Claim for Medical Monitoring?
}

Thomas J. Miceli and Kathleen Segerson

\begin{abstract}
Traditional tort law does not allow a victim of exposure to a toxic substance to seek damages without evidence of actual loss. Given the difficulty of collecting damages after a long latency period, however, we examine the desirability of granting exposure victims an independent cause of action for medical monitoring at the time of exposure. We show that such a cause of action is not necessary to induce victims to invest in efficient monitoring. It can, however, increase incentives for injurer care, but only at the cost of greater litigation costs. The general reluctance of courts to adopt a cause of action reflects their recognition of this trade-off.
\end{abstract}

\section{INTRODUCTION}

Under the traditional law of torts, victims cannot sue for damages without evidence of actual loss. For example, a victim of exposure to a hazardous substance who has not developed symptoms of illness does not have a cause of action because, as a leading case book notes, "The threat of future harm, not yet realized, is not enough."1 However, several commentators have noted that this requirement erects undue barriers to recovery for exposure victims because, given the long latency period of many illnesses, it is often difficult at the time of illness to establish a causal connection between the exposure and the illness. This is especially true of illnesses for which there is a background risk unrelated to the exposure. Even when causation can be established, however, statutes of limitations and statutes of repose, as well as the potential for injurer insolvency, may

\footnotetext{
${ }^{1}$ Keeton, et al. (1984: p. 165). To assert a tort claim, a victim must prove harm, causation, and, in the case of negligence, breach of duty.
} 
render the injurer judgment proof. $^{2}$ These problems undermine both the compensatory and the deterrence functions of tort law. ${ }^{3}$

One proposed solution is to give plaintiffs an independent cause of action, at the time of exposure, for recovery of reasonable medical monitoring costs. ${ }^{4}$ It is an established practice for courts to award such expenses to exposure victims, along with ordinary damages, at the time they actually develop symptoms ${ }^{5}$ the question of interest here is whether an independent claim for such costs should exist. The medical benefit of awarding medical monitoring at exposure, it is argued, is to promote early detection and improved treatment of the illness. ${ }^{6}$ It therefore serves to "mitigate" the damages from exposure (Shavell, 1987: pp. 158-159). An offsetting cost is the prospect of a "flood" of litigation, "potentially absorbing resources better left available to those more seriously harmed..."7 After weighing these factors, the U.S. Supreme Court, in Metro-North Commuter Railroad v. Buckley, ${ }^{8}$ denied a claim for medical monitoring by a railroad worker exposed to asbestos. The Court noted that, although several state supreme courts have allowed such claims, ${ }^{9}$ they have done so subject to certain limitations in recognition of the offsetting factors. ${ }^{10}$ The Court therefore concluded that creation of a separate

\footnotetext{
${ }^{2}$ On statutes of limitations and statutes of repose, see Miceli (2000). On the judgment-proof problem, see Shavell (1986) and Beard (1990).

${ }^{3}$ See, generally, Landes and Posner (1984), Robinson (1985), and Slagel (1988).

${ }^{4}$ See, e.g., Slagel (1988) and Hamrick (1998).

${ }^{5}$ For example, in Metro-North Railroad Co. v. Buckley, 521 U.S. 424, 438 (1997) the Court stated that "... an exposed plaintiff can recover reasonable medical costs if and when he develops symptoms."

${ }^{6}$ See Slagel (1988). In Metro-North v. Buckley, (1997: p. 443), the Court stated that “...providing preventive care to individuals who would otherwise go without can help to mitigate potentially serious future health effects of diseases by detecting them in early states..."

${ }^{7}$ Metro-North v. Buckley, (1997: p. 442). Also see Hamrick (1998).

${ }^{8} 521$ U.S. 424 (1997).

${ }^{9}$ See the survey of state treatments of medical monitoring claims in Joyce (2001).

${ }^{10}$ In particular, the courts have noted the inappropriateness of lump-sum damages, suggesting instead the creation of court-supervised funds for medical monitoring or the use of insurance mechanisms (See MetroNorth v. Buckley, 1997: pp. 440-441).
} 
cause of action for medical monitoring was not justified on policy grounds and went "beyond the bounds of currently 'evolving common law.","11

To date there has been no explicit economic analysis of the desirability of allowing a tort claim for medical monitoring. ${ }^{12}$ In this paper, we develop a simple model to examine whether, or under what conditions, allowing such a claim would enhance social efficiency in the sense of reducing total social costs. We first consider a world of zero litigation costs. In that context, we show that allowing a separate claim has no effect on efficiency. Victims choose the efficient amount of mitigation and injurers choose the efficient amount of care regardless of whether a separate claim is allowed, provided awards are appropriately adjusted. However, in the more realistic world where litigation is costly, allowing a separate claim for medical monitoring can affect social costs. On the one hand, creation of an independent action for medical monitoring increases the number of suits faced by injurers. This increases litigation costs, which, ceteris paribus, increases social costs. On the other hand, injurer costs go up as well, thereby increasing injurer care. This decreases social costs because, in the presence of litigation costs, injurers are under-deterred by standard liability rules. Whether allowing a separate action for medical monitoring increases or decreases social costs therefore depends on the relative magnitude of these two effects. This conclusion reflects the general trade-off between litigation (enforcement) costs and deterrence in a costly legal system (Becker, 1968; Shavell, 1982; Hylton, 1990).

While we are unaware of any previous studies that examine explicitly the efficiency of independent medical monitoring claims, some previous studies have

\footnotetext{
${ }^{11}$ Metro-North v. Buckley, (1997: p. 440) (quoting Consolidated Rail Corp. v. Gottshall, 512 U.S. 532, 558 (1994).
} 
examined closely related issues, and we build on these analyses. For example, Landes and Posner (1984) examined the ability of tort law to deal with the problem of catastrophic, or large scale, accidents, including mass exposures to a toxic substance. After noting the above problems with the traditional tort-for-illness rule in this context, they proposed a rule that allows victims to file at exposure for expected damages. They did not, however, explicitly address the desirability of allowing recovery for medical monitoring (in addition to expected damages) at the time of recovery.

Rose-Ackerman (1989) considered a seemingly unrelated setting — a case of trespass - that nevertheless raises closely related issues. Suppose a mining company builds a dam, creating the risk of a flood (if the dam bursts) that would cause damage to a downstream landowner. The owner, foreseeing the risk, builds a dike to protect her property. Should the owner be allowed to seek compensation from the mining company for the cost of the dike? Efficiency dictates that the answer is yes, for otherwise, the mining company will underestimate the cost of building the dam. Allowing recovery, however, raises the question of when the landowner can file suit. Rose-Ackerman shows that two timing rules are equally efficient: one that allows the landowner to sue at the time the dam is built for the cost of the dike plus expected flood damages, and one that only allows a suit in the event of a flood for actual damages plus a multiple of the cost of the dike.

Note that the first rule, if applied to the toxic tort context, would embody a claim for medical monitoring (in addition to expected damages) because it allows the owner to seek compensation for his precautionary behavior at the time the expenditure is undertaken, i.e., prior to the occurrence of an accident. The second also allows recovery

\footnotetext{
${ }^{12}$ But see Bathgate (2001).
} 
for medical monitoring expenses, but only by victims who actually suffer damages. We demonstrate the efficiency of Rose-Ackerman's two timing rules in the context of the model of toxic torts developed here, and also consider a third that allows two separate actions, one for recovery of medical monitoring expenses at the time of exposure, and one for compensatory damages at the time of illness.

The remainder of the paper is organized as follows. Section 2 sets up the general exposure model assuming zero litigation costs, and shows the conditions under which each of the three timing rules leads to efficient care by injurers and efficient medical monitoring (mitigation) by victims. The results imply that all three rules induce efficient behavior by both parties, provided damages are appropriately defined. Section 3 , however, shows that when litigation costs are taken into account, this conclusion is no longer true. In particular, whereas allowing a separate tort for medical monitoring at the time of exposure improves incentives for injurer care, it results in higher costs of litigation. In light of this trade-off, the desirability of allowing such a claim depends on a balancing of these two effects. Finally, Section 4 concludes.

\section{THE MODEL WITH ZERO LITIGATION COSTS}

We first consider a world in which litigation costs are zero. This allows us to focus on the incentive effects of the various rules regarding recovery of medical monitoring expenses. The notation of the model is as follows:

$$
\begin{aligned}
& p(x) \quad=\text { probability of exposure to a toxic substance; } \\
& x \quad=\text { injurer care, } p^{\prime<0}, p^{\prime \prime} 0 \\
& q \quad=\text { probability of illness given exposure; } \\
& D(M)=\text { damages in the event of illness; }
\end{aligned}
$$


$M \quad=$ expenditure on medical monitoring by the exposure victim, $D^{\prime}<0, D^{\prime \prime}>0$.

The model is one of "sequential care" along the lines of that in Wittman (1981) and

Shavell (1983). ${ }^{13}$ That is, the injurer moves first and chooses a level of care that

determines the risk of exposure. Then, if an exposure occurs, the victim chooses a level

of medical monitoring aimed at mitigating the expected loss. ${ }^{14}$

\section{A. Social Optimum and Filing Rules}

Since the parties act sequentially, we derive the social optimum by considering their optimal care choices in reverse order. Thus, in the event of an exposure, the victim's problem is to choose the level of medical monitoring, $M$, to minimize her expected costs

$$
M+q D(M)
$$

which yields the first-order condition

$$
1+q D^{\prime}=0 .
$$

Denote the solution to (2) by $M^{*}$. Given optimal monitoring by the victim, the injurer's problem is to choose care, $x$, to minimize

$$
x+p(x)\left[M^{*}+q D\left(M^{*}\right)\right]
$$

which yields the first-order condition

$$
1+p\left\{M^{*}+q D\left(M^{*}\right)\right]=0 .
$$

Let $x *$ be the solution to (4).

\footnotetext{
${ }^{13}$ Also see Shavell (1987: pp. 158-159), who discusses the closely related issue of mitigation of damages by victims.

${ }^{14}$ Note that the victim's damage in the event of an illness, $D(M)$, is written as a function of the latter's investment in medical monitoring, while the probability of illness conditional on exposure, $q$, is not. This reflects the idea, noted above, that the primary benefit of monitoring is to detect and mitigate the illness rather than to prevent it. Ordinarily, it is not necessary to be explicit about the components of expected damages in accident models; all that matters is the product, $q D(M)$. However, given that we are interested in the timing of lawsuits, the probability of illness, $q$, will be important for calculating the proper measure of damages at exposure versus at illness, and, when litigation is costly, for determining the expected number of suits under the various filing rules
} 
Shavell (1983) and Wittman (1981) have characterized the ability of various liability rules to achieve the efficient outcome in sequential care accidents under the condition that the victim can only file at illness. ${ }^{15}$ Here, the focus is on the timing of lawsuits. We therefore restrict attention to a rule of strict liabililty, and consider three alternative rules that differ the timing of recovery and whether an independent action for recovery of medical monitoring is allowed. The three rules we consider are as follows: Rule 1: Tort for Illness. This is the traditional common law rule under which the victim can only file suit at illness. At that time, she can seek both compensatory damages and reasonable medical monitoring expenses.

Rule 2: Tort for Exposure. Under this rule, the victim can only file at exposure but can seek both medical monitoring costs and expected damages.

Rule 3: Separate Action for Medical Monitoring. Under this rule, the victim can file a separate suit at exposure for medical monitoring costs and can then file again at illness for damages.

Note that rules 1 and 2 are the two proposed by Rose-Ackerman (1989), while Rule 3 "decouples" compensatory damages and medical monitoring. In the next section we examine the conditions (if any) under which these rules can achieve the efficient outcome as derived above.

\section{B. Injurer and Victim Care}

As above, we proceed in reverse sequence. Thus, we first consider the victim's incentives for medical monitoring following an exposure. We begin by defining the general compensation rule $C(M) \geq 0$, which represents the present value of any payments that the victim expects to receive under the relevant timing rule as of the time she chooses

\footnotetext{
${ }^{15}$ Also see Miceli (1997), Chapter 3.
} 
$M .^{16}$ This general function can be defined to embody compensation under any of the three rules that we consider. Note that, when compensation is awarded only if the victim becomes ill, $C(M)$ embodies the probability $q$ of receiving compensation.

Given this rule, the victim's problem can be written generally as

$$
\text { Minimize } M+q D(M)-C(M)
$$

which yields the first-order condition

$$
1+q D^{\prime}-\frac{\partial C}{\partial M}=0
$$

Comparison of (2) and (6) immediately implies that $\partial C / \partial M \equiv 0$ in order for the victim to choose $M^{*}$. That is, under any of the timing rules, expected compensation to victims must be lump sum, or independent of their actual choices of $M$. (It follows that compensation must also be independent of their actual damages, $D(M).)^{17}$ Thus, as long as compensation is lump sum, the victim will be induced to choose the efficient amount of medical monitoring regardless of whether medical monitoring expenses can be recovered at the time of exposure or only if and when illness occurs. This suggests that, in the context of zero litigation costs, allowing recovery by all victims at the time of exposure rather than only by illness victims at the time of illness will not lead to additional investment in medical monitoring. In other words, allowing a separate recovery at the time of exposure is not necessary to promote expenditures on early detection and mitigation. ${ }^{18}$

Given lump sum compensation of $C\left(M^{*}\right)$, we can characterize the injurer's choice of care under any of the three rules as the solution to

\footnotetext{
${ }^{16}$ For simplicity, we ignore discounting in the formal analysis.

${ }^{17}$ Landes and Posner (1984) and Rose-Ackerman (1989) also make this point.
} 


$$
\text { Minimize } x+p(x) C\left(M^{*}\right)
$$

Comparison of (3) and (7) implies that the injurer will choose efficient care if and only if

$$
C\left(M^{*}\right)=M^{*}+q D\left(M^{*}\right)
$$

Equation (8) implies the following efficient versions of the above filing rules:

Rule 1: The injurer is liable at illness for $M^{*} / q+D\left(M^{*}\right) .{ }^{19}$

Rule 2: The injurer is liable at exposure for $M^{*}+q D\left(M^{*}\right)$.

Rule 3: The injurer is liable at exposure for $M^{*}$ and at illness for $D\left(M^{*}\right)$.

Under Rule 1, the traditional rule, victims are precluded from filing at exposure. Thus, in addition to paying reasonable compensatory damages, injurers must also pay a multiple of the victim's reasonable monitoring expenses, where the multiplier is the inverse of the probability of developing an illness given exposure (i.e., $1 / q$ ). This multiplier reflects the fact that victims (efficiently) invest in precaution at the time of exposure, but, under Rule 1 , they can only sue for the resulting cost with probability $q$. Thus, in the absence of the multiplier, the injurer will avoid paying $M^{*}$ a fraction $1-q$ of the time, which will cause him to underestimate the social cost of exposure. For example, if courts award $M^{*}+D\left(M^{*}\right)$ under Rule 1 (in effect reimbursing victims for their actual monitoring costs), injurers will choose too little care.

A further drawback of the multiplier is that it only compensates victims on average. Specifically, exposure victims who become ill will receive compensation that exceeds their efficient investment in medical monitoring $\left(M^{*} / q>M^{*}\right)$, whereas exposure victims who never contract the illness will receive no compensation for their monitoring

\footnotetext{
${ }^{18}$ Note that this ignores any potential wealth constraints a victim might face, which could limit the ability of victims to invest efficiently.

${ }^{19}$ To see that this rule is efficient, note that the injurer's problem is to minimize $x+p(x) q\left[M^{*} / q+D\left(M^{*}\right)\right]$, which is clearly equivalent to (3).
} 
expenses. These concerns provide a rationale (apart from consideration of litigation costs) for allowing recovery of medical monitoring costs at the time of exposure (as is provided by Rules 2 and 3).

Rules 2 and 3 both allow a cause of action even if no actual symptoms of illness have arisen. Under Rule 2, victims can only sue at exposure (i.e., a suit at exposure precludes any further suits). Thus, in order to achieve the efficient outcome victims must be able to collect both "reasonable" medical monitoring expenditures plus the damages that they expect to incur if these precautions are taken. The damages are thus discounted by the probability of illness, $q .{ }^{20}$ In contrast, under Rule 3, victims can sue at exposure for reasonable medical monitoring, and then again at illness (should it occur) for reasonable damages. In this case, efficiency is ensured if they receive reasonable medical monitoring expenses at the time of exposure and then the associated damages if and when an illness occurs.

The preceding shows that victims will be induced to invest efficiently in monitoring and injurers will choose efficient care regardless of when recovery for medical monitoring is allowed, given the proper definition of damages. In other words, allowing a separate action for medical monitoring will not affect the incentives of either victims or injurers. This conclusion, however, has not accounted for litigation costs, which, it has been argued, may make suits for exposure too costly from a social perspective. ${ }^{21}$ We address this issue in the next section.

\footnotetext{
${ }^{20}$ See Landes and Posner (1984), Robinson (1985), and Rose-Ackerman (1989).

${ }^{21}$ An offsetting benefit of suits for exposure, which we ignore here, arises from the fact that injurers may be judgment-proof at the time an illness occurs, especially if the latency period is long. See, e.g., Slagel (1988).
} 


\section{THE MODEL WITH LITIGATION COSTS}

To incorporate the impact of litigation costs, let

$$
\begin{aligned}
& c_{i}=\text { injurer's litigation costs, } \\
& c_{v}=\text { victim's litigation costs. }
\end{aligned}
$$

In general, litigation costs can affect the victim's decision of whether or not to file suit, her expenditure on medical monitoring, and the injurer's choice of care. Additionally, they affect the definition of social costs because the number of suits becomes endogenous depending on the legal rule. We first consider the victim's filing decision and investment in medical monitoring.

\section{A. Victim's Filing Decision and Care Choice}

The victim's filing decision depends on the specific timing rule because the rules differ both in the point at which the victim can file suit, and in the amount that she can recover. For example, under Rule 3, the victim can file at exposure for $M^{*}$ and again at illness for $D\left(M^{*}\right)$. We assume that suits at each point in time cost the same amount, $c_{v}$. Thus, under this rule, at the time of exposure the victim will file a separate action for recovery of medical monitoring expenses if

$$
M^{*} \geq c_{v}
$$

She will then file again at illness (if it occurs) if

$$
D\left(M^{*}\right) \geq c_{v}
$$

We assume that both conditions hold. This is sufficient to assure that all possible suits will occur not only under Rule 3 but under the other two rules as well. This assumption 
allows us to most fully account for the impact of litigation costs on the comparison of the various legal rules. $^{22}$

We now re-consider the victim's investment in medical monitoring under each of the filing rules. Under Rule 1, the victim files at illness for $M^{*} / q+D\left(M^{*}\right)$. Thus, her problem at the time of exposure is to choose $M$ to

$$
\text { Minimize } M+q D(M)-q\left[M^{*} / q+D\left(M^{*}\right)-c_{v}\right]
$$

Since the term in brackets is independent of $M$, the victim chooses $M^{*}$, the socially efficient level of monitoring. Intuitively, the victim's choice of $M$ has no effect on the amount of her compensation (because it is lump sum) or on her expected litigation costs (because $q$, the probability of illness, is constant). ${ }^{23}$ Thus, the victim has no incentive to distort her choice of $M$ and chooses the efficient level.

Under Rule 2, the victim files at exposure for an amount $M^{*}+q D\left(M^{*}\right)$. Her optimization problem is therefore to

$$
\text { Minimize } M+q D(M)-\left[M^{*}+q D\left(M^{*}\right)-c_{v}\right]
$$

which, for the reasons noted above, yields the efficient level of medical monitoring. Finally, under Rule 3, the victim files at exposure for $M^{*}$, and at illness (should it occur) for $D\left(M^{*}\right)$. Her optimization problem in this case is to

$$
\text { Minimize } M+q D(M)-\left(M^{*}-c_{\nu}\right)-q\left[D\left(M^{*}\right)-c_{v}\right]
$$

which again yields $M^{*}$.

The analysis in this section has shown that the addition of litigation costs does not alter the victim's choice of medical monitoring, which continues to be efficient under all

\footnotetext{
${ }^{22}$ More generally, the cost of litigation will deter some victims from filing suit (see, e.g., Hylton, 1990). Allowing this would significantly complicate the analysis but would not alter our qualitative results.

${ }^{23}$ Suppose instead that $q$ were decreasing in $M$. The first-order condition arising from (11) would then include an extra term, $-q^{\prime}\left(D\left(M^{*}\right)-c_{v}\right)$, which is positive given (10). Thus, the victim would choose $M<M^{*}$,
} 
three rules. The reason is that the victim views the probability of a suit, and hence her expected litigation costs, as independent of her choice of $M$. Thus, even when litigation costs are positive, allowing a separate suit for recovery of medical monitoring at the time of exposure is sufficient but not necessary to induce the victim to invest in the efficient amount of monitoring. That investment will be efficient even if recovery is only allowed if and when an illness occurs, provided compensation is lump sum and expenditure on monitoring affects only the damages that would result if an illness occurs (and not the probability of contracting the illness). ${ }^{24}$

\section{B. The Number of Suits and Social Costs}

The preceding analysis of victim filing decisions can now be used to determine the number of suits under the various filing rules. Let $n_{j}$ be the expected number of suits (or, more precisely, the probability of a suit) conditional on an exposure, under rule $j$. Given our assumption that all possible suits are filed, we have:

$$
n_{1}=q, \quad n_{2}=1, \quad n_{3}=1+q
$$

Under Rule 1, only illness victims file suit. The expected number of suits is thus given by the probability that an exposure victim will contract the illness (and hence file suit), which is simply $q$. Under Rule 2, all exposure victims file a single suit with certainty. Thus, the expected number of suits under this rule is simply 1. Finally, if a separate action is allowed for recovery of medical monitoring expenses at the time of exposure (Rule 3), all exposure victims will file a medical monitoring suit with certainty, and a

or too little monitoring. It will be seen that a similar moral hazard problem would exist under the other two rules.

${ }^{24}$ If $q$ is a function of $M$, then expected litigation costs will no longer be independent of $M$ under Rules 1 and 3 . 
fraction $q$ of these will file an additional suit at the time of illness. The expected number of suits under this rule is thus $1+q$.

It follows from (14) that the rules can be ranked in terms of the expected number of suits as follows:

$$
n_{3}>n_{2}>n_{1} .
$$

This provides the basis for the claim that allowing a separate claim for medical monitoring expenses will produce a "flood" of litigation compared to the traditional rule (especially if $q$ is small).

Since suits are costly, the definition of social costs in this section will depend on $n_{j}$. As shown above, all three rules result in efficient medical monitoring by victims. Thus, we can write social costs under rule $j$ as follows:

$$
S C_{J}=x_{j}+p\left(x_{j}\right)\left[M^{*}+q D\left(M^{*}\right)+n_{j}\left(c_{i}+c_{v}\right)\right] .
$$

Note that this differs from (1) only by the addition of the litigation cost term in square brackets. It follows from (16) that if $x$, like $M$, were invariant to the legal rule, we could use (15) to rank the rules in terms of social costs since they would differ only in the amount of the expected litigation costs. However, unlike the victim's choice of medical monitoring, the injurer's choice of care is not invariant to the legal rule, as we show in the next section.

\section{Injurer Care}

Given the care and filing decisions of victims, we can write the injurer's costs under Rule $j$ as

$$
I C_{j}=x_{j}+p\left(x_{j}\right)\left[M^{*}+q D\left(M^{*}\right)+n_{j} c_{i}\right] .
$$


Note that this differs from social costs by the absence of the victim's expected litigation costs, $n_{j} c_{v}{ }^{25}$ The injurer's optimal care choice under Rule $j$ solves the first-order condition

$$
1+p\left\{M^{*}+q D\left(M^{*}\right)+n_{j} c_{i}\right]=0 .
$$

Denote the solution to this by $x^{*}\left(n_{j}\right)$. Comparison of (18) and (4) shows that the injurer takes more care than when litigation is costless, ${ }^{26}$ but he takes less care than is socially optimal in a world of costly litigation because he ignores the victim's cost of litigation. ${ }^{27}$ Further, differentiation of (18) shows that $\partial x *\left(n_{j}\right) / \partial n_{j}>0$. The injurer takes more care as the number of suits increases because by doing so, he reduces his expected litigation costs, given by $p(x) n_{j} c_{i}$.

The fact that injurer care is increasing in $n$ creates an ambiguity in the comparison of the three rules. To see this formally, differentiate the minimized value of social costs in (16) to obtain

$$
\begin{aligned}
\frac{\partial S C_{j}^{*}}{\partial n_{j}} & =\frac{\partial x_{j}^{*}}{\partial n_{j}}+p^{\prime} \frac{\partial x_{j}^{*}}{\partial n_{j}}\left[M^{*}+q D\left(M^{*}\right)+n_{j}\left(c_{i}+c_{v}\right)\right]+p\left(c_{i}+c_{v}\right) \\
& =p^{\prime} \frac{\partial x_{j}^{*}}{\partial n_{j}} n_{j} c_{v}+p\left(c_{i}+c_{v}\right) \underset{<}{\gtrless} 0
\end{aligned}
$$

where the second line is obtained by using (18). The first term in (19), which is negative, reflects the reduction in social costs resulting from greater deterrence as the number of suits increases. This is a social benefit because, as noted, the injurer ignores the victims' litigation costs and hence takes too little care from a social perspective. The second term,

\footnotetext{
${ }^{25}$ If some victims do not file suit because of the cost of litigation, (17) would also exclude their damages (Hylton, 1990).

${ }^{26}$ Note in particular that $x *$ from the previous section corresponds to $x *(0)$ in the current notation.
} 
which is positive, captures the offsetting increase in social costs as total litigation costs rise. This reflects the concern about the volume of litigation under a tort for exposure. The implication is that, when litigation costs are taken into account, the three filing rules cannot be ranked unambiguously in terms of social costs. Choosing the optimal rule therefore becomes an empirical question based on a balance of deterrence versus litigation costs. In particular, when a separate claim for medical monitoring is allowed, there is no effect on the victim's monitoring choice but the number of suits is increased.

This increase in the number of suits has an ambiguous effect on social costs. On the one hand, it leads to increased care by injurers, which ceteris paribus reduces social costs, but on the other, it leads to higher litigation costs, which increase social costs. The net effect on social costs depends on which of these effects is larger. Thus, with costly litigation, allowing a separate claim for medical monitoring will not necessarily increase social welfare. This conclusion is consistent with the general trade-off, well known in the law-and-economics literature, between litigation costs and deterrence. Specifically, suits are socially desirable only if the reduced accident costs owing to greater injurer care offset the costs of litigation (Shavell, 1982; Hylton, 1990). ${ }^{28}$

How do these results relate to actual legal practice? Generally, courts have been reluctant to recognize a tort for exposure (as embodied in Rules 2 and 3), even in the absence of medical monitoring. This may reflect their judgment that the potential deterrence benefits are outweighed by the additional litigation costs. One might be tempted to argue that the mitigation benefits of medical monitoring, when available,

\footnotetext{
${ }^{27}$ If some victims do not file suit, the injurer's care would fall further below the social optimum and may even fall below the zero-litigation-cost optimum.
} 
would tip the balance in favor of allowing exposure suits. Our results show, however, that such suits are not in fact necessary to induce exposure victims to invest in efficient medical monitoring — indeed all three rules, if properly designed, yield the correct incentives for victims. This conclusion is consistent with the Supreme Court's decision to deny an independent action for medical monitoring in Metro-North, and the fact that, to date, only six states have adopted such an action (Joyce, 2001).

\section{CONCLUSION}

This paper has examined the question of whether victims of accidental exposure to a toxic substance should be allowed to seek compensation for medical monitoring costs prior to the onset of symptoms. Traditionally, the law has not recognized a separate cause of action for medical monitoring, a view that was recently affirmed by the U.S. Supreme Court. However, some state courts have begun to permit such claims under limited conditions. The question we address is how a tort for medical monitoring will affect the social costs associated with accidental exposures. The specific conclusions of the analysis are as follows.

1. One argument in support of a claim for medical monitoring is that it will encourage exposure victims to seek early detection and treatment of the threatened illness, thereby efficiently mitigating the damages. We showed that this is not necessarily the case. In particular, if victims receive lump sum compensation for reasonable medical monitoring expenses, then they will invest in efficient monitoring regardless of whether the compensation is awarded before or after the onset of the illness.

\footnotetext{
${ }^{28}$ This same trade-off arises in any context where enforcement of the law is costly. Becker (1968) was one of the first to point his out when he showed that optimal deterrence of crime balances the enforcement costs (including apprehension, and, when relevant, imprisonment costs) against the benefits of deterrence.
} 
2. In the absence of litigation costs, allowing a separate claim for medical monitoring has no effect on injurer care or social costs. Given the appropriate definition of damages, it is possible to achieve the first-best outcome for both victim and injurer care, regardless of whether a separate claim is allowed or not.

3. An important factor in discussions of medical monitoring is the potential for a flood of litigation. We showed that when litigation costs are taken into account, the desirability of allowing a claim for medical monitoring hinges on a trade-off between the increased number of suits, which raises social costs, and increased injurer care, which lowers social costs by reducing the amount of underdeterrence. Efforts to quantify these costs would therefore seem to be a necessary component of the debate about whether or not to allow claims for medical monitoring. 


\section{REFERENCES}

Bathgate, J. (2001). The Influence of a Tort for Risk on the Incentive to File Suit in a Costly Legal System. Ph.D. Dissertation, Univ. of Connecticut, Dept. of Economics.

Beard, T. R. (1990). Bankruptcy and Care Choice. Rand Journal of Economics, 21, 626634.

Becker, G. (1968). Crime and Punishment: An Economic Approach. Journal of Political Economy, 76, 169-217.

Hamrick, M. (1998). Comment: Theories of Injury and Recovery for Post-Exposure, PreSymptom Plaintiffs: The Supreme Court Takes a Critical Look. Cumberland Law Review, 29, 461-488.

Hylton, K. (1990). The Influence of Litigation Costs on Deterrence under Strict Liability and under Negligence. International Review of Law and Economics, 10, 161-171.

Joyce, S. (2001). Medical Monitoring: Are Some States Walking into a Legal Thicket? ALEC Policy Forum, 3, 20-25.

Keeton, W., D.Dobbs, R. Keeton, and D. Owen (1984). Prosser and Keeton on Torts $\left(5^{\text {th }}\right.$ ed.). St. Paul, MN: West Publishing Co.

Landes, W. and R. Posner (1984). Tort Law as a Regulatory Regime for Catastrophic Personal Injuries. Journal of Legal Studies, 13, 417-434.

Miceli, T. (1997). Economics of the Law. New York: Oxford Univ. Press.

Miceli, T. (2000). Deterrence, Litigation Costs, and the Statute of Limitations for Tort Suits. International Review of Law and Economics, 20, 383-394.

Robinson, G. (1985). Probabilistic Causation and Compensation for Tortious Risk. Journal of Legal Studies, 14, 779-798.

Rose-Ackerman, S. (1989). Dikes, Dams, and Vicious Hogs: Entitlements and Efficiency in Tort Law. Journal of Legal Studies, 18, 25-50.

Shavell, S. (1982). The Social versus Private Incentive to Bring Suit in a Costly Legal System. Journal of Legal Studies, 11, 333-339.

Shavell, S. (1983). Torts in which Victim and Injurer Act Sequentially. Journal of Law and Economics, 26, 589-612. 
Shavell, S. (1986). The Judgment Proof Problem. International Review of Law and Economics, 6, 45-58.

Shavell, S. (1987). Economic Analysis of Accident Law. Cambridge, MA: Harvard Univ. Press.

Slagel, A. (1988). Medical Surveillance Damages: A Solution to the Inadequate Compensation of Toxic Tort Victims. Indiana Law Journal, 63, 849-876.

Wittman, D. (1981). Optimal Pricing of Sequential Inputs: Last Clear Chance, Mitigation of Damages, and Related Doctrines in the Law. Journal of Legal Studies, 10, 6591. 